\title{
ALGEPS
}

REVISTA DE GEOLOGIA, SÈRIE B $n^{\circ} 610$ - Desembre del 2012

ISSN $1132-7014$

D.L.B. 28.178 - 92

10 pàgines

\section{RECORREGUT DE RECERCA GEOLÒGICA I GEOAMBIENTAL PER LES COMARQUES D'ANOÍA I DE LA SEGARRA: DES D'IGUALADA I CASTELLOLÍ CAP A JORBA, CARBASÍ I A SANT PERE DELS ARQUELLS}

Josep M. Mata-Perelló i Joaquim Sanz Balagué

Aquest recorregut va ésser experimentat amb docents el dia 8 DE MARÇ DEL 2011 


\section{RECORREGUT DE RECERCA GEOLÒGICA I GEOAMBIENTAL PER LES COMARQUES D'ANOÍA I DE LA SEGARRA: DES D'IGUALADA I CASTELLOLÍ CAP A JORBA, CARBASÍ I A SANT PERE DELS ARQUELLS / 8 DE MARÇ DEL 2011}

Per Josep M. MATA-PERELLÓ i Joaquim SANZ i BALAGUÉ

\section{ADVERTIMENTS PREVIS}

Com en altres recorreguts de RECERCA GEOLÒGICA I MINERALÒGICA ..., si es disposa del temps suficient, poden efectuar-se passant per totes les parades i filloles. En cas contrari, recomanem prescindir de les anomenades PARADES - CONDICIONALS.

També cal tenir en conte que part del recorregut, tant a l'inici de l'itinerari, com als seus darrers trams, es realitzarà per camins de terra, per la qual cosa caldrà prendre les degudes precaucions.

Cal tenir, com sempre, una cura molt especial de respecte a la natura, al llarg de tot el recorregut de l'itinerari, i també fora d'ell.

\section{BREU INTRODUCCIÓ}

En aquesta ocasió, es realitzarà un recorregut geològic a través de diferents indrets de la Depressió Geològica de L'Ebre; i més concretament pels sectors corresponents a la seva Depressió Central. Així, tot el recorregut transitarà entre afloraments dels materials terciaris (de l’Eocè i de l'Oligocè) i quaternaris que reblen aquesta depressió.

Així, inicialment es transitarà per la comarca d'Anoia (per on discorrerà la primera part de l'itinerari), per a penetrar després a la comarca de la Segarra, per on finalitzarà a les immediacions de la ciutat de Cervera, a Sant Pere dels Arquells.

\section{OBJECTIUS FONAMENTALS D’AQUEST ITINERARI}

Els objectius fonamentals que es pretenen aconseguir en aquest itinerari, es poden concretar en els següents aspectes generals:

1.- Observació i descripció dels materials terciaris (exclusivament del Paleogen, i més concretament de l’Eocè i de l’Oligocè) de la Depressió Geològica de l'Ebre (i més 
exactament de la seva Depressió Central). Així, el recorregut de l'itinerari discorrerà entre els afloraments de la Formació Tossa (de l'Eocè), els del Complex Lacustre d'Anoia (amb la Formació Artés, del trànsit de l'Eocè a l'Oligocè) i els del Complex Lacustre de la Segarra (amb les calcàries de la Panadella, ja de l'Oligocè). Tots aquests terrenys constitueixen el subsòl dels diferents sectors, per entre els quals discorre el present itinerari.

2.- Observació de les estructures locals de la Depressió Geològica de l'Ebre, al llarg del recorregut de l'itinerari; tot i això, no cal oblidar que el recorregut transitarà per una de les zones més laxes de la depressió, alterada solament per alguns plecs relacionats amb els nivells de guixos.

3.- Observació i reconeixement de les mineralitzacions evaporítiques guixoses situades pels voltants de Jorba, a la comarca d'Anoia. Aquests materials, en aquest indret, es relacionen amb la Formació Artés.

4.- Observació de les explotacions relacionades amb els materials anteriors, com les següents, d'acord amb el sentit de la marxa de l'itinerari:

4A) de les ja esmentades explotacions guixoses de les Guixeres de Jorba, situades entre els materials de la Formació Artés.

4B) de les explotacions de les calcolutites rogenques de la Formació Artés, situades prop de Sant Genís, també dintre de la comarca d’Anoia

4C) de les explotacions dels materials carbonatats de la Panadella-Carbasí, (dintre de la comarca d'Anoia), relacionades sobre els nivells de les calcàries de la Panadella de la Formació Tàrrega.

4D) i de les explotacions de calcolutites grisenques, situades entre els guixos de Talavera (de la Formació Tàrrega), que trobarem a Sant Pere dels Arquells (en aquest cas dintre de la comarca de la Segarra).

5.- En tots els casos, a les explotacions anteriors, s'observaran les restauracions efectuades en elles.

6.- S’observaran, al llarg de tot el recorregut, els diferents elements relacionats amb el Patrimoni Geològic i Miner.

\section{ANTECEDENTS BIBLIOGRÀFICS}

Pel que fa al recorregut del present itinerari, existeixen diversos antecedents bibliogràfics. Entre aquests, farem esment de dos treballs nostres, els quals segueixen uns recorreguts bastant semblants i propers al present. Es tracta de: MATA-PERELLÓ (1996a, 1996b, 1996c, 1997, 1999, 2000 i 2001a, 2001b, 2005a i 2005b).

Pel que fa a la descripció de les mineralitzacions, seguirem fent esment d'alguns altres treballs nostres: MATA-PERELLÓ (1990, 1991 i 1995); el primer relatiu a la comarca d'Anoia, el segon al conjunt de les les mineralitzacions catalanes i el tercer a la Segarra. També cal parlar del treball de COLLDEDORNS i MATA-PERELLÓ (1995). 
I, finalment, pel que fa a l'estructura geològica de la zona per la qual discorre l'itinerari, farem esment dels treballs de: GUIMERÀ et altri (1982) i de RIBA et altri (1976). També es pot fer esment del treball de COLLDEFORNS - MATA (1987)

Tots aquests treballs referenciats, i d'altres, figuren esmentats per ordre alfabètic a l'apartat dedicat a la BIBLIOGRAFIA.

\section{RECORREGUT DE L'ITINERARI}

El recorregut de l'itinerari discorrerà quasi íntegrament per les comarques de l'Anoia i de la Segarra dintre de la Catalunya Central. Així, el recorregut de l'itinerari, s'iniciarà al terme d'Igualada. Tot seguit, el recorregut es dirigirà cap a Sant Genís, on es farà una aturada. Després es continuarà cap a ponent, seguint sempre per la carretera nacional N-II, passant per Jorba i deixant després enrere el trencall de Calaf.

Posteriorment, després de retornar des de la guixera a la carretera nacional, es seguirà cap a ponent, passant-se prop de Santa Maria del Camí. Després es seguirà cap a la Panadella i cap Carbasí, per on s’efectuarà una nova aturada, prop de la Panadella.

Després, des la Panadella, es continuarà cap a ponent per la carretera comarcal que es dirigeix cap a Sant Antolí i Vilanovai cap a Rubinat, per on es farà una altra parada. Finalment, des de Rubinat caldrà anar cap a Hostalet i cap a les immediacions de de Sant Pere dels Arquells, prop d'on es farà la darrera aturada i finalitzarà aquest itinerari, molt prop de Vergós i de la ciutat segarrenca de Cervera.

\section{DESCRIPCIÓ DE L'ITINERARI}

Com de costum, estructurarem el recorregut de l'itinerari en una sèrie de PARADES, que anirem veient. En cadascuna d'aquestes aturades farem un breu comentari (geològic o mineralògic, segons s'escaigui). En cada cas indicarem, entre parèntesi, el full topogràfic on es troba l'aturada. En aquest cas, el recorregut de l'itinerari s'inclourà dintre dels següents fulls, del "Mapa Topográfico Nacional", realitzats a l'escala 1:50.000 per l'I.G.C. de España": 390 (dit de Cervera) i 391 (o d’Igualada).

Així doncs, la relació de les aturades, que composen el recorregut d’aquest itinerari és la següent

PARADA 1. TRAM DE L'AUTOVIA DELS VOLTANTS DE JORBA, (terme municipal de Jorba, comarca de l'Anoia). (Full 391)

Tot i que el recorregut l'iniciarem a la ciutat d'Igualada, ens caldrà l'Autovia A-2, per tal de fer un recorregut cap a ponent, cap a les immediacions de Sant Genís i de Jorba. En aquest cas, caldrà fer una “ATURADA EN MARXA”, per tractar-se d'una via de circulació ràpida. En qualsevol cas, des de la parada anterior, haurem recorregut uns $4 \mathrm{Km}$, des de l'inici. 
En el recorregut, des de la parada anterior, hem trobat primer els nivells calcolutítics de la Formació Igualada, en sortir Igualada. Per sobre, hem trobat els de guixos d'Òdena, i més amunt les calcolutites i els gresos rogencs de la Formació Artés, integrants del Sistema lacustre de l'Anoia En bona part d'aquest recorregut, el trajecte va serpentejant entre uns altres materials.

Aquests, ocasionalment es troben replegats, com succeeix prop del trencall de l'Espelt. Aquests plecs, que afecten als nivells de guixos (i també als trams inferiors de la Formació Artés que cobreixen als anteriors) són de vegades força vistosos. Per d'altra banda, els trams de calcolutites de la Formació Artés es caracteritzen aquí per ser molt argilosos

Sovint, als marges de l'Autovia trobarem plegats i replegats uns i altres materials. Més endavant, prop de Sant Genís. Veurem com hi ha hagut trams de l'Autovia que han tingut freqüents esllavissades, com a conseqüència de la plasticitat dels materials anteriors, de l'acció de les obres i de l'aigua. També es poden veure les obres de consolidació efectuades, per tal d'evitar les esllavissades.

\section{PARADA 2. EXPLOTACIONS CALCOLUTÍTIQUES DE SANT GENÍS, (Sant Genís, terme municipal de Jorba, comarca d’Anoia). (Full 391).}

Des de la parada “atípica” anterior, cal agafar des de l'Autovia el trencall que es dirigeix cap a Sant Genís. En arribar-hi, ens caldrà fer una aturada a les explotacions de calcolutites, situades a la vora de l'antiga carretera N-II. Així, des de la parada anterior, s'haurà fet un recorregut proper als 1'5 Km, per tal d'arribar fins aquí.

En el recorregut, des de la parada anterior, hem anant trobant els materials ja esmentats de la Formació Artés, d'intensos colors rogencs, clarament continentals. Com ja hem dit a l'aturada anterior, els trams de calcolutites d'aquesta Formació Artés es caracteritzen aquí per ser molt argilosos.

I, aquests són precisament els materials que es troben al mateix indret de l'aturada, on són explotats, com a material ceràmic, per tal d'ésser emprats en unes plantes de fabricació de materials ceràmics molt properes a la carretera. A l'actualitat aquesta empresa es troba en plena activitat (febrer del 2011).

En tot cas, per fer aquesta aturada, caldrà demanar una autorització a l'empresa minera que explota les calcolutites.

PARADA 3 - CONDICIONAL. GUIXERA DE JORBA, (terme municipal de Jorba, comarca de l'Anoia). (Full 391)

Després de fer la parada anterior, cal fer un recorregut per la carretera nacional $\mathrm{N}$-II tot anant sempre cap a ponent. Així, aviat s'arribarà a la població de Jorba, que caldrà sobrepassar. Poc després es trobarà per la dreta el trencall que s'encamina cap a Copons i Calaf. Més endavant s'arribarà a l'àrea de Servei. Aquí, caldrà passar a l'altra banda, per tal d'agafar després el camí que es dirigeix cap a les Guixeres de Jorba i cap a 
Clariana després. En arribar a les guixeres caldrà fer una nova aturada, a uns $5 \mathrm{Km}$ de l'anterior feta a Sant Genís.

En aquest recorregut, haurem trobat els materials ja esmentats anteriorment de la Formació Artés. Entre aquests nivells rogencs es fan cada vegada més palesos uns trams de guixos (els Guixos de Clariana), que aquí són explotats. Tot i així, per entrar a la Guixera, cal la oportuna autorització.

A la guixera, actualment abandonada, es poden veure clarament els nivells de guixos explotats. Entre els, es fan clarament palès el GUIX LAMINAR, molt ostentós. Es tracta sempre de guixos secundaris.

\section{PARADA 4. EXPLOTACIÓ DE CALCÀRIES DE MONTMANEU, (terme municipal de Montmaneu, comarca d'Anoia, subcomarca de la Segarra Anoienca). (Full 390).}

Després de fer la parada anterior, cal retornar cap a la carretera N-II (i si s'escau a la Autovia A-2), per tal de fer un recorregut, tot anant sempre cap a ponent. Així, aviat s'arribarà a la petita població de Santa Maria del Camí, que caldrà sobrepassar. Més endavant es trobaran per l'esquerra els trencalls de Porqueres i d'Argençola. Finalment, en arribar a l'inici de la pujada que condueix cap a la Panadella, trobarem un camí per la dreta. Aquest camí condueix en uns $100 \mathrm{~m}$ cap a unes antigues pedreres de calcàries, on farem la present aturada, després d’haver recorregut uns $10 \mathrm{Km}$ des de la parada anterior.

En aquest recorregut s'han tallat inicialment els nivells rogencs de la Formació Artés dels que hem parlat a la parada anterior. I més exactament dels anomenats guixos de Clariana.. Continuant per aquesta carretera, prop del trencall d'Argençola, s'han començat a fer palesos uns nivells de calcàries cada cop més potents. Aquests nivells corresponen a les calcàries d'Albarells, integrades dintre de la Formació Tàrrega.

Precisament, a l'indret de l'aturada es troba una antiga explotació d'aquests materials carbonatats acabats d'esmentar. Aquests van ésser explotats per a la fabricació d'àrids. A l'actualitat la pedrera es troba aturada.

PARADA 5. EXPLOTACIÓ DE CALCÀRIES DE LA PANADELLA, (la Panadella, terme municipal de Montmaneu, sector segarrenc de la comarca d’Anoía). (Full 390).

Després de fer la parada anterior, cal retornar a la carretera N-II (al tram antic), per tal de pujar cap al Port de la Panadella , vora el poble del mateix nom. Des d'aquí cal agafar primer la carretera B-221, per la dreta, tot anant cap a ponent. Poc després de sobrepassar el trencall de Carbassí (per l'esquerra), començarem a trobar explotacions de calcàries (també a l'esquerra de la carretera). Aquí farem la una aturada, a menys de 1'5 Km de sortit de la Panadella, i a uns $5 \mathrm{Km}$ de la parada anterior.

En aquest breu recorregut, hem tallat els trams carbonatats, esmentats a la parada anterior. Tot seguit haurem tallat uns nivells de calcolutites i gresos, $\mathrm{i}$ ben aviat uns altres 
trams carbonatats, que també que pertanyen a la Formació Tàrrega. Aquests són els nivells de les "calcàries de la Panadella" i són els que es troben a l'indret on ara som. Aquí, aquests materials carbonatats són explotats en una pedrera. Així, els materials extrets són emprats per a la construcció com a àrids. A tal efecte, hi ha una planta matxucadora i classificadora dels materials estrets.

Cal fer esment de que les calcàries que aquí afloren, d'aspecte molt tablejades, són les que en erosionar-se i ésser transportades pel riu d'Ondara i pel riu Corb, són les que han proporcionat la matèria prima dels còdols de les pedreres d'àrids i d'arenes situades pels voltants de Bellpuig (a la comarca de l'Urgell). Tanmateix són els materials que en erosionar-se han donat lloc als dipòsits pleistocens de l’Urgell i del Pla d'Urgell.

Per d'altra banda, aquestes calcàries de la Panadella, fan palès un típic relieve en cuesta. El que constitueix la cuesta de la Panadella - Montmaneu. Aquesta "cuesta" dona lloc a una clara divisòria d'aigües, entre els rius afluents del Segre (Corb, Ondara i Sió) i els que menen a la xarxa de la Mediterrània Oriental (especialment l'Anoia; i també prop de Santa Coloma de Queralt, el riu Gaià).

PARADA 6. BALNEARI DE RUBINAT, ELS BANYS DE RUBINAT, (Rubinat, terme municipal de Sant Antolí i Vilanova, comarca de la Segarra). (Full 390).

Després de fer l'aturada anterior, cal continuar per la carretera $\mathrm{N}$ - II anant cap a ponent. Així, s'arribarà al trencall de Sant Antolí i Vilanova i Hostalet, des d'on es pot anar cap a Rubinat, i cap als Banys, per on farem una nova aturada, a uns $7 \mathrm{Km}$ de l'anteriorment realitzada.

En aquest recorregut, hem deixat enrere les calcàries de Montmaneu i la Panadella, i hem anat trobant afloraments dels guixos de Talavera (amb guixos, gresos i calcolutites). Aquests materials també pertanyen a la Formació Tàrrega, de la qual n’he parlat anteriorment. Precisament en aquest indret afloren els guixos i calcolutites blanques de l'esmentada Formació Tàrrega. Per arreu es fan clarament paleses les antigues fonts de característiques salines (clorurades, carbonatades i sulfatades). Aquestes aigües han estat utilitzades en uns antics banys, els Banys de Rubinat.

$\mathrm{Al}$ respectem, cal dir que en aquest indret, hi ha un important Patrimoni Miner, pel qual es fa necessària una correcta valoració del mateix , per tal de conèixer-lo i evitar la seva possible degradació. Alhora, també es fa necessària una necessària protecció del mateix. Aquests restes comprenen: les surgències de l'aigua, un edifici molt degradat, les vivendes. Tot i així es fa necessària una urgent dedicació.

PARADA 7 - CONDICIONAL. FORNS DE CALÇ $i$ FORNS DE GUIX DE RUBINAT - L'HOSTALET, (Rubinat i Hostalet, terme municipal de Sant Antolí i Vilanova, comarca de la Segarra). (Full 390).

Després de fer l'aturada anterior, cal retornar cap al poble de Rubinat, per tal de baixar després per la carretera que es dirigeix cap a l'Hostalet (cap a la vella N-II). En 
aquest trajecte, d'uns $4 \mathrm{Km}$, podem fer una aturada a qualsevol dels antics Forns de Calç o Forns de Guix, que hi a l'esquerra de la carretera, tot baixant.

En aquest recorregut, hem continuat trobant els materials abans esmentats dels guixos de Talavera, amb afloraments de nivells calcolutítics blanquinosos i de guixos. Mot sovint, hem trobat indrets on han estat explotats aquests materials, amb restes de forns de guix i de forns de calç. Tots ells formen part del nostre Patrimoni Miner.

PARADA 8. CAMÍ DE MAS CLARET, (Sant Pere dels Arquells, terme de Sant Antolí, comarca de la Segarra). (Full 390).

Des de la parada anterior, cal acabar d'arribar a l'Hostalet, per tal de continuar cap a llevant (ara per la carretera N-II, tot descendent per la vall del Riu d'Ondara. Després, en arribar a la cruïlla de Sant Pere dels Arquells, cal agafar el camí que surt per la banda dreta de la carretera (en sentit oposat a la carretera que condueix al poble esmentat). Així cal agafar el camí que en un principi es dirigeix cap a Mas Claret, per tal de fer una fillola. Així, s’hauran recorregut uns $4 \mathrm{Km}$ i escaig.

A molt poca distancia de l'inici del camí (a uns $10 \mathrm{~m}$ ), es troba un trencall per l'esquerra, que condueix a unes antigues explotacions dels guixos de la sots-unitat dels guixos de Talavera, situades molt a prop.

Tanmateix es troben uns antics forns de guix (PARADA 8-BIS). Entre els minerals presents a aquests antics nivells explotats, cal fer esment de la presència d'ANHIDRITA, HEMIHEDRITA i GUIX (el més abundant dels tres),

Malgrat això, el camí principal (el que condueix cap a Mas Claret), ens apropa a uns forns de tostació de materials margosos, on són tractats els extrets d'una propera pedrera, actualment en explotació, que es troba a l'esquerra del camí principal.

En aquesta parada, es pot observar l'explotació de les calcolutites blanquinoses, de la Formació Tàrrega, i alhora es poden observar les instal-lacions dels forns. Tot i així, per a l'observació dels esmentats forns de tostació, i de la pedrera en explotació, es necessari gaudir de la corresponent autorització de l'empresa minera concessionària de l'esmentada explotació. 


\section{REFERÈNCIES BIBLIOGRÀFIQUES}

COLLDEFORNS, B. I MATA-PERELLÓ, J.M. (1987).- Inventari mineralògic de la comarca de la Segarra, Xaragall, nº 18, 32 pag. Manresa

GUIMERÀ, J. et altri (1992).- Geologia (II), Història Natural dels Països Catalans, Vol.2, 547 pag. Enciclopèdia Catalana, S.A. Barcelona

MATA-PERELLÓ, J.M. (1990).- Inventari Mineralògic de la comarca d'Anoia. Revista Xaragall, $\mathrm{n}^{\circ}$ 24, 40 pag. Manresa

MATA-PERELLÓ, J.M. (1991).- Els Minerals de Catalunya. Arxius de la Secció de Ciències, t. XCIII, 442 pag. Institut d'Estudis Catalans. Barcelona

MATA-PERELLÓ, J.M. (1996a).- Recerca geològica i mineralògica per les comarques d'Anoia, Segarra, Conca de Barberà, Urgell i Noguera: des de la Panadella a Preixens. Inèdit, 18 pàgines. Manresa

MATA-PERELLÓ, J.M. (1996b).- Selecció d'Itineraris Geològics i Mineralògics per les terres de Lleida, Pub. EUPM-Museu de Geologia, 65 pàgines. Manresa

MATA-PERELLÓ, J.M. (1996c).- Recerca geològica i mineralògica per les comarques d'Anoia, Segarra, Conca de Barberà, Segarra i Urgell: des de Jorba a Preixens. Inèdit, 19 pàgines, Manresa

MATA-PERELLÓ, J.M. (1997).- Recerca geològica i mineralògica per les guixeres de la comarca d'Anoia: des d'Òdena i l'Espelt a Jorba i a Clariana. Inèdit, 11 pag. Manresa

MATA-PERELLÓ, J.M. (1999).- Recerca geològica i mineralògica per la comarca d'Anoia: des d'Òdena i l'Espelt a Jorba, i des de Clariana i Argençola a Bellmunt i Aguiló. Inèdit, 10 pag. Manresa

MATA-PERELLÓ, J.M. (2000).- Recerca geològica i de reconeixement dels georrecursos per les pedreres de la comarca d'Anoia: des d'Odena i l'Espelt a Sant Martí de Tous, i des de Clariana i Argençola a Carbasí. Algeps, sèrie B, $\mathrm{n}^{\circ}$ 172, 11 pag. Manresa

MATA-PERELLÓ, J. M. (2001a).- Recerca geològica i geoambiental per les comarques d'Anoia i de la Segarra: des d'Òdena i l'Espelt cap a Sant Genís i Jorba, i des de Montmaneu a Sant Pere dels Arquells. Inèdit, 8 pàgines. Manresa

MATA-PERELLÓ, J. M. (2001b).- Recorregut de recerca de geologia ambiental per les comarques de la Segarra, de l'Urgell i de les Garrigues: des la Panadella i Santa Coloma de Queralt cap a Guimerà i cap a Belianes. Inèdit, 10 pag. Manresa

MATA-PERELLÓ, J. M. (2005a).- Recorregut de recerca geològica i geoambiental per les comarques d'Anoia i de la Segarra: des d'Igualada i Castellolí cap a Jorba, Carbasí, Rubinat i Cervera. Inèdit. 10 pàgines. Manresa 
MATA-PERELLÓ, J. M. (2005b).- Recerca geològica i mineralògica per les comarques d'Anoia, de la Baixa Segarra (Conca de Barberà) i de la Segarra: des de Jorba i Montmaneu a Rauric i a Rubinat. Inèdit. 8 pàgines. Manresa

MATA-PERELLÓ, J.M. i COLLDEFORNS, B. (1995).- Introducció al coneixement geològic de la Segarra. Coneix. de l'entorn natural de la Segarra, $\mathrm{n}^{0}$ 7, 29pag. Cervera

RIBA, O. et altri (1976).- Geografia Física dels Països Catalans, Edit. Ketres, 254 pàgines. Barcelona 